\title{
Reconceptualizing cultural literacy as a dialogic practice
}

\author{
Fiona Maine and Victoria Cook* - University of Cambridge, UK \\ Tuuli Lähdesmäki - University of Jyväskylä (JYU), Finland
}

\begin{abstract}
Culture and heritage are plural and fluid, continually co-created through interaction between people. However, traditional monologic models of cultural literacy reflect a one-way transmission of static cultural knowledge. Using the context of a large European project and augmenting the work of Buber with models of literacy as social practice, in this article cultural literacy is reconceptualized as fundamentally dialogic. We argue that cultural literacy empowers intercultural dialogue, opening a dialogic space with inherent democratic potential. Considering implications for the classroom, we outline how a dialogic pedagogy can provide a suitable context for the development of young people's cultural literacy.
\end{abstract}

Keywords: dialogue, cultural literacy, new literacies, intercultural dialogue

\section{Introduction}

The twenty-first century has intensified a movement of people within and across state borders, and a major challenge is the building of societies that reflect inclusion and collaboration where children and young people can learn 'to know', 'to do', 'to live together' and 'to be' (UNESCO, 1996: 20-1). In a new European Horizon 2020 project, Dlalogue and Argumentation for cultural Literacy Learning in Schools (DIALLS), these ideas are explored as the project addresses the role of formal education in shaping the knowledge, skills and competences needed for effective cultural literacy learning, intercultural dialogue and mutual understanding.

Beyond traditionally describing reading and writing, the term literacy is often used generally to describe competency in a particular field. To be literate is to be competent and knowledgeable. The term is used to normalize understanding, so we describe people as being emotionally literate or financially literate to indicate a certain competence and skill set. The original concept of cultural literacy can be seen in alignment with this, adopting literacy as a desirable standard with the stance that culture is a set of knowledge to acquire and that those most literate are those well versed in this knowledge set. As the most frequently cited author writing about cultural literacy, Hirsch (1988) even created a list of 5,000 names, dates, phrases and ideas that every American needs to know. The idea of a fixed set of knowledge that might then be used to form a 'curriculum for all' in formal education has had an uptake in the UK too, most significantly by right-wing think tanks, which have found it an appealing move away from the more skills driven focuses that were prevalent in the early twentyfirst century (Young et al., 2014).

In the DIALLS project we argue that seeing cultural literacy as knowledge attainment reduces it to a monologic concept that conveys a one-way transmission 
of cultural knowledge as something removed from everyday living. Instead, drawing on an extensive review of European educational policy documentation and scholarly literature, we explore how cultural identities and heritages are fluid and pluralistic in modern society. In this article we illustrate how the direction of our research leads us to move beyond a concept of cultural literacy as being about knowledge of culture, into a consideration of cultural literacy as a dialogic practice enabled through constructive encounters about what it means to be different from each other.

Using Street's (1984) model of literacy as a social practice, we view cultural literacy in the context of multiliteracies (New London Group, 1996) and propose that it is in fact dispositional and dialogic. Drawing on Buber's (1958) notion of I-Thou as a relational and reciprocal concept of being, we reconceptualize the static, passive model of cultural literacy to propose a dynamic, fluid and creative concept of positive engagement with diversity. Becoming 'culturally literate' thus means to be disposed to be, and competent in being, sensitive to one's own and others' identities, heritages and cultures. Finally, we consider what this means for the classroom and propose that, not only is the concept of cultural literacy dialogic, but also that it is through dialogic pedagogy that we can encourage our young people to become tolerant, empathetic and inclusive of other positions and perspectives.

\section{Traditional models of cultural literacy}

Hirsch (1980), a liberal philosopher of education, first challenged the idea of literacy as culturally neutral when he noted a decline in the quality of students' writing. $\mathrm{He}$ attributed this decline to a disregard for the cultural dimension of writing, which he defined as 'that whole system of unspoken, tacit knowledge that is shared between writer and reader' (ibid.: 29). He termed this intergenerational, shared canonical knowledge 'cultural literacy'. Hirsch argued that cultural literacy must entail both common pieces and types of knowledge that lead to shared experiences. He argued at length that the achievement gap between privileged and underprivileged students can be explained by variations in exposure to this cultural knowledge. His liberal perspective led him to champion cultural literacy as a means of breaking the cycle of poverty and illiteracy to facilitate communication with strangers, which he argued was necessary to 'promote the general welfare and to ensure domestic tranquillity' (Hirsch, 1988: xii). If people were able to draw on the same cultural knowledge then they would be better able to communicate in equal terms. The importance for Hirsch, then, was that this knowledge set was stable, traditional and reliable in order to be commonly accessed. Hirsch felt he was moving beyond a narrow conceptualization of culture as an acquaintance with the arts by proposing his list of cultural items as a 'vivid system of shared associations' (ibid.: 127).

Critiques of Hirsch's work are commonly concerned with the association with traditionalism, elitism and representation as noted by Edwards (1984: 71), who argued that the list's Anglo-Saxon focus undermined the values of cultural diversity and would lead to a 'rigid, tradition-based book list' that would be 'too elitist, too exclusionary'. Defending the association with traditionalism, Hirsch (1988: xii) noted the unavoidable paradox that 'the goals of political liberalism require educational conservatism'. Reiterating his earlier argument that cultural literacy was necessary to facilitate communication among diverse cultures, he stressed that 'no single national vocabulary is inherently superior or privileged above all others' (ibid.: 107). However, critics have continued to associate Hirsch's traditionalism with elitism (Aronowitz and Giroux, 2003; Hendley, 1989; Graf, 1989; McLaren, 1998; Woodhouse, 1989). Early 
accusations, in response to the original cultural list, focused in part on the exclusion of ethnic and youth cultures, and the marginalization of science and technology in favour of the more static elements of elite culture (Woodhouse, 1989). Interestingly, none of these critiques highlight what we would call the 'monologic essence' of Hirsch's model - that culture is merely something to be accessed or 'read'. This is illustrated by Woodhouse (1989: 87), who in his critique of Hirsch argues that 'the world is a text to be interpreted, criticized, and reinterpreted'. Missing from Woodhouse's critique is that culture is not just received (even if critiqued and reinterpreted), it is also created. Giroux (1992: 233), however, did recognize this, arguing that Hirsch's view ignores 'how schools and other institutions function as complex sites of cultural production'. He also criticized Hirsch for depoliticizing the issue of culture and presenting 'a single durable history and vision, one at odds with a critical notion of democracy and difference' (ibid.: 94).

There has been significant purchase for Hirsch's ideas in recent years within the reframing of the National Curriculum in England. Discussions around content and knowledge have been at the forefront of this debate, particularly in humanities subjects, in particular in geography, where arguments for a 'public sphere of knowledge that enables all cultural groups to engage with common issues and debates' abound (Lambert, 2011: 254). Questions of pragmatism and social realism have engaged scholars making a case for a return to a concentration on knowledge rather than the seemingly amorphous soft skills of life-long learning that were more dominant in the early twenty-first century (see, for example, Biesta, 2014; Young et al., 2014). Arguments are concerned with the concept of disciplinary knowledge or 'powerful knowledge' (Young, 2009), but attention is also drawn to the underpinning epistemologies that inform assumptions about how curricula are or might be created (Scott, 2014) and whether curriculum content is based on foundationalism (considering what it is legitimate to include), instrumentalism (inclusion on the basis of the use of knowledge) or pragmatism (considering the consequences of including particular content) (ibid.). Advocates argue that 'cultural literacy does not negate the "multi-cultural society" but it does challenge the idea that local groups need not assimilate a wider "national" culture, indeed it shows that it is in their interest to do so' (Lambert, 2011: 254). However, none of these positions truly challenge the notion of cultural literacy from the alternative viewpoint to question if there is more to being 'culturally literate' than having knowledge about culture. Our analysis of educational policy documentation from the Council of Europe and the European Union (DIALLS, 2018) draws out key themes related to cultural heritages, identities and values that extend beyond sets of knowledge that are shared or 'enduring' (Swift, 2017). The analysis highlights the importance of engagement with the cultural diversity of society, including knowledge and sensitivities about our own cultural identities. To a degree this can be seen to resonate with Hirsch's argument that one must understand one's own culture first before becoming more broadly literate second (Hirsch, 1988), though our analysis leads us to argue that it is the disposition to engage together that sits as the central tenet to cultural literacy.

Kaufer (1989), who was broadly supportive of Hirsch's focus on the cultural aspect of literacy, sought to develop the theoretical underpinnings of his work, reasoning that the theory of cultural literacy as 'sharing' lacked any sense of empowerment for the individual. He proposed an alternative theory of cultural literacy as 'contributing', arguing that 'unless we hope to contribute to what we share, sharing is an authoritarian exercise rather than a legitimate tool of democracy' (ibid.: 25). According to Kaufer, a theory of contributing shifts the content focus from the extensive cultural list towards 
issues (for example, democracy, freedom or paternalism). Such an approach, in which the teaching of issues can still be tied to the teaching of specific texts, should empower students 'to follow and, eventually, to lead our most important cultural conversations' (ibid.: 28). Additionally, Riecken and Court (1992) proposed to extend Hirsch's concept to include the ability to read the explicit and implicit messages embodied in popular culture. To do this they stressed the importance of employing critical thinking skills rooted in a strong value base that emphasizes respect for individuals. These existing refinements of the original model of cultural literacy are useful in moving towards a dialogic concept that seeks to recognize the pluralistic nature of a multicultural world and the dispositions needed to navigate it.

\section{Why reconceptualize cultural literacy?}

The monologic understanding of cultural literacy reflects a notion of culture as an objective, static and top-down imposed value system transmitted to future generations through selected cultural canons. The creation and transmission of these canons construct static cultural understandings of 'us' as a homogeneous national community and of the 'others' beyond or external to it, and maintains the idea of cultural differences between 'us' and 'them'. Cultural canons also effectively create and transmit static notions of heritage and present certain artefacts and traditions as important to be fostered as unchanged. Linking culture, heritage and identity to nations and nationalities has been for a long time - and often still is - a common and even naturalized way to perceive national self-understandings as well as cultural differences. This linkage forms a key to what Malkki (1992: 24, 1995: 512) has described as the 'national order of things' and Löfgren (1989: 21-2) as an 'international cultural grammar of nationhood' that are still kept up and maintained in diverse ways in modern societies - even in practices, such as in intercultural education, that seek to overcome simplifying categorizations of people based only on their nationality or ethnicity.

The idea of becoming 'culturally literate' by familiarizing with one's own and others' culture and heritage through selected artefacts and cultural traditions has serious limitations. First, it does not recognize culture and heritage as inherently plural and as a constantly transforming and fluid collective action (and therefore as a social construction) based on interaction between diverse people (Otten, 2003; AbdallahPretceille, 2006). Second, the emphasis on factual knowledge of culture and heritage as a key element for cultural encountering may cause people to be perceived as stable representatives of their (national) culture. This may lead to cultural stereotyping and categorizing that obstructs the perception of people as individuals, and may therefore even bring about prejudices (Abdallah-Pretceille, 2006; Portera, 2008). Third, increasing cultural pluralism and hybridity and global cultural flows challenge the top-down nation-building projects, the creation of cultural canons as well as the whole 'national order of things', in Malkki's (1992: 24, 1995: 512) terms.

Modern societies are characterized by a plurality of cultures and heritages as well as divergent, even competing, narratives and notions of cultural artefacts and traditions. The individual's identity-building process thus always occurs in relation to surrounding 'super-diversity' (Vertovec, 2007) and social interaction with other people and their identity-building processes. This social interaction is a key for constructing one's own cultural identity as well as to encounter other people and face cultural differences. It is indeed the social interaction of people in cultural encounters that the concept of cultural literacy should address and seek to promote. 
Many Western countries have recognized the pluralization of modern societies as a richness that, however, entails diverse challenges if the encountering of cultures is not based on mutual understanding and respect. Various political actors, such as the Council of Europe and the European Union, have brought forth 'intercultural dialogue' as a policy to enhance 'an open and respectful exchange of views between individuals, groups with different ethnic, cultural, religious and linguistic backgrounds and heritage' (Council of Europe 2008: 10-11). As a policy, intercultural dialogue seeks, for example, 'to develop a deeper understanding of diverse perspectives and practices; to increase participation and the freedom and ability to make choices; to foster equality; and to enhance creative processes' (Wiesand et al., 2008: xiii). Intercultural dialogue as a policy needs more concrete tools through which it can be implemented. The DIALLS' reconceptualization of cultural literacy emphasizes an individual's disposition and competence to encounter cultural differences and to elaborate one's own identity in respectful social interaction with other people. With this reconceptualization, we seek to emphasize the very idea of intercultural dialogue.

\section{Alternative models to support the reconceptualization of cultural literacy}

If traditional models of cultural literacy can be seen as monologic, one-way transmissions of accessing culture, in proposing a reconceptualization of this attention now turns to focus specifically on the concept of literacy and the changing models that have tried to define it. Traditional models of literacy have been argued to be autonomous (Street, 1984, 2003), setting writing at the heart of literacy accomplishment, and regarding it as 'supposedly technical and neutral' (Street, 1984: 29). One is either literate or illiterate, and the notion of literacy is a normative and fixed achievement.

In his seminal works, Freire (2000; Freire and Macedo, 1987) concentrated on the power of literacy to overcome oppression in society. He argued that it is impossible to separate the world from the word, arguing that 'the transformation of objective reality (what I call the writing of reality) represents precisely the starting point where the animal that becomes human began to write history' (Freire and Macedo, 1987: 33). For Freire, it was not viable to 'separate literacy from the productive process of society' (ibid.: 33). Writing with Freire, Macedo (ibid.: 32) noted:

the notion of emancipatory literacy suggests two dimensions of literacy. On the one hand students have to become literate about their histories, experiences and the culture of their immediate environment. On the other hand they must also appropriate those codes and cultures of the dominant spheres so they can transcend their own environments.

To read the world, then, one must be able to read the word (Freire and Macedo, 1987), becoming literate to access culture and knowledge. The monologic nature of the traditional, or as Street (1984) termed, 'autonomous' model of literacy presupposes that writing allows access to culture, as opposed to an engagement with or even a creation of it through a fluid, social and dialogic practice.

In arguing against the traditional model of literacy, Street proposed what he termed an 'ideological' model that sets literacy as a social practice, recognizing the mix of oral and written practices within situated contexts. For Street (2003: 79), 'literacy practices, then, refer to the broader cultural conception of particular ways of thinking about and doing reading and writing in cultural contexts'. Drawing on Street's work, New Literacies Studies theorists and in particular the New London Group, proposed a model 
of literacy, or rather 'multiliteracies', that sits comfortably with Street's 'ideological' model of literacy as a social practice. In their manifesto (New London Group, 1996) they described traditional models of literacy as page-bound, monolingual, monocultural and rule governed. They set out to extend the scope of literacy to 'account for the context of our culturally and linguistically diverse societies' (ibid.: 61). Their concept of multiliteracies captures a 'multiplicity of channels and communication' and the 'increasing saliency of cultural and linguistic diversity' (ibid.: 63). These sociocultural models question the dominance of some voices and the marginalization of others (Street, 2003), and call for recognition of the different practices appropriate to different cultural situations. What Freire and Macedo (1987) define as the appropriation of codes and cultures is the point at which the dialogic concept of cultural literacy can begin and the 'ideological' model can be seen to represent a more two-way concept of literacy that culture is a product of social practice and literacy a cultural expression, rather than a passive response to a dominant, elitist set of products and values. Moreover, Street's model moves beyond the Freirean concept of emancipatory literacy or critical literacy as it recognizes not only the dominant literacy practices in society as being desirable, but also fluid and interactional social practices in perhaps more marginalized contexts.

So why is it important to turn to newer models of literacy to help define cultural literacy? First, if a monologic, that is 'autonomous', model of literacy is defined as a set of skills - learning to read and write in a page-bound world - we argue that a monologic/autonomous model of cultural literacy includes sets of knowledge about culture (cf. Hirsch) and skill sets to achieve it. If Street's model of literacy as a social practice of meaning-making and communication is seen as a fluid and dialogic model, then a similar dialogic model of cultural literacy is less about accessing fixed cultural knowledge and more about creating and responding to culture through social practices and engagement. Further to this, a dialogic model then can identify cultural literacy as a social practice, using Street's definition to help refine the concept. If cultural literacy necessarily includes notions of the social, then it is about more than individuals and their relationship to culture, but also how they then engage with each other. This centralizes social interaction as key to understanding one's own cultural identity and acknowledging cultural differences. To move from a monologic model of cultural literacy to a dialogic one considers how people are disposed to engage together through social interaction with their cultural identities, heritages and values, creating fluid and changing cultural practices that celebrate difference and alternative perspectives.

\section{Cultural literacy as a dialogic practice}

Buber's (1958) writing on the difference between the monologic mode of I-It and the dialogic mode of $I$-Thou is useful for our reconceptualization of cultural literacy as a dialogic practice. For Buber, the I-It mode objectifies the world, separating the subject from the object, with the I of the primary word rooted in the past. If we apply Buber's work to understanding culture, according to this mode culture is objectified as a 'thing', or collections of 'things', to be used or experienced. Here we can see how Buber's account of the I-It mode aligns with Hirsh's monologic, and largely historical, view of cultural literacy. However, if, as we have argued, cultural literacy is about engaging with each other, as well as with culture, then we need to move beyond the I-It stance to culture.

Buber's accounts of dialogue with nature in the I-Thou mode suggest that dialogue is a relational event that moves beyond the self/other distinction. In this 
sense, dialogue can be understood as more than intersubjectivity (Wegerif and Major, 2019). Rather, it is an experience of wholeness (Buber, 1958). The notion of the I-Thou mode enables one to enter into relation with both another person and, we would argue, with culture (values, heritages and identities). According to Buber, in this mode the I of the primary word is rooted in the present and the relation between I and Thou is mutual, 'My Thou affects me, as I affect it' (ibid.: 12). Thus both 'I' and 'culture' affect each other. Dialoguing with culture in the I-Thou mode therefore underpins the continual evolution of culture and aligns with our understanding of culture as dynamic co-construction, lived in the present and not solely rooted in the past.

As Wegerif (2016) argues, one implication of Buber's main thesis 'is that when we observe the world in "l-it" mode we fix a world of distinct objects and when we observe in "I-thou" mode we open up a very different world of entangled relationships and possibilities of learning across apparent boundaries' (ibid.: n.p.). By taking an I-Thou attitude to culture one therefore stands in relation to culture, which opens up possibilities for learning. Inevitably, through these learning experiences, one must move back into the world of $I$-It, but the continual movement from I-Thou to $\mathrm{l}$-It is what captures the essence of cultural literacy as a two-way, dialogic practice.

Crucially, this is an ongoing process. Dialogue is infinite in nature; as Bakhtin (1986) argued, there can be no last word in dialogue. Given the ongoing and fluid nature of dialogue, it may open up a shared, unbounded space of potential meaning that has been referred to as 'dialogic space' (Wegerif, 2007). Within dialogic space, difference is both created and explored (Wegerif, 2010). The dialogic space opened up by the reconceptualization of cultural literacy as dialogic thus creates a borderless space with inherent democratic potential. It is within this space that cultural identities and heritages, which are both fluid and pluralistic, can be created as well as explored. Wegerif (2011: 182) wrote:

People always have irreducibly different perspectives on the world because we have different bodies and histories. Even when we think that we agree about concepts we inevitably understand those concepts differently. This is not to suggest that achieving 'common ground' is not important in dialogues but that it is one moment in a larger flow of meaning that is more fundamentally described as the tension between different perspectives held together in proximity around a dialogic gap. If there is no gap then there is no dialogue and if there is no dialogue then there is no meaning.

This sentiment echoes Freire's (2000: 92) argument that 'without dialogue there is no communication and without communication there can be no true education'. For Freire it is through dialogue that the world is named and then transformed. He argued that, 'this dialogue cannot be reduced to the act of one person's "depositing" ideas in another, nor can it become a simple exchange of ideas to be "consumed" by the discussants' (ibid.: 89).

\section{Implications for pedagogy}

Reconceptualizing cultural literacy as a dialogic practice affords the potential for new expression and collaboration. It transcends consideration of 'my culture and your culture' into a transformational concept that opens up a dialogic space between people in which culture is created. Thus, cultural literacy becomes the process of engaging with cultures, the disposition to do so and the creation and expression of cultural identities and values. 
Following the UNESCO (1996) four pillars of education, learning how to both 'live together' and 'to be' centralizes the importance of cultural literacy as it has been reconceptualized here, but also highlights the need for dialogic experiences for children to explore their own, and others', cultural values, heritages and identities. A pedagogy that supports this is necessarily dialogic (Alexander, 2008) offering spaces for the co-construction of ideas and understanding. Not only is cultural literacy then fundamentally dialogic, a pedagogy that promotes understanding, respect and valuing as we have described is paramount in its promotion; a pedagogy where dialogue is actively encouraged and solutions are not neatly sought, but alternative perspectives are appreciated and included as positive. Navigating the dialogic gap between these different perspectives relies on trust and mutual respect, and an environment where principles of dialogic learning lead to a collective, reciprocal and supportive ethos (ibid.).

Such a pedagogy helps to recognize that 'there is no necessary equality between the voices: everyone brings something different, some their great experience, others their curiosity and innocence - all are valued' (Wegerif, 2018: n.p.). Furthermore, it is underpinned by an environment where teachers and students listen carefully to each other, build on different ideas, position themselves and acknowledge changes of mind. A dialogic ethos is central to the aims of the DIALLS project where we actively teach students to engage productively with each other, utilizing the skills of dialogue and argumentation in classroom discussions. However, learning to be sensitive to one's own and others' identities, heritages and cultures is not the same as being disposed to do so. It is the regular experience of these competences that make them second nature or automatic or 'relatively stable habits of mind and body' (Scott, 2014: 16) in order to engage in the dialogic practice of cultural literacy, and thus a responsibility of school leaders to enable and promote such practice within classrooms.

Reconceptualizing cultural literacy as enabled through constructive encounters significantly centralizes rhetoricity within the concept of culture, with cultural identities understood as discursive (Lähdesmäki, 2012) rather than static, restricted or monologic. Cultural literacy can then be viewed not as a set of facts and achievements referring to a specific group of people, but as a dialogic social practice.

\section{Acknowledgement}

This project has received funding from the European Union's Horizon 2020 research and innovation programme under grant agreement No 770045 .

\section{Notes on contributors}

Fiona Maine is Senior Lecturer in Literacy Education at the University of Cambridge. She is the principal investigator for the EC Horizon 2020 project, Dlalogue and Argumentation for cultural Literacy Learning in Schools (DIALLS). Her research investigates the dialogic interactions of children as they make meaning together from visual, moving image and digital narratives, and highlights the possibilities afforded by working with non-verbal and ambiguous texts in the classroom.

Victoria Cook is Research Associate at the Faculty of Education, University of Cambridge. She is currently working on the DIALLS project and is also investigating the use of digital technology to support classroom dialogue on the DiDiAC (Digitalised 
Dialogues Across the Curriculum) project. Prior to joining the Faculty in 2016, Victoria worked as a secondary school geography teacher.

Tuuli Lähdesmäki is Senior Researcher, ERC Starting Grant Holder and Adjunct Professor in the Department of Music, Art and Culture Studies, University of Jyväskylä (JYU), Finland. Besides conducting research in her ERC project on European cultural heritage and identity politics, she works as one of the PIs in the JYU's research profiling area Crises Redefined and leads the JYU research team in the DIALLS project.

\section{References}

Abdallah-Pretceille, M. (2006) 'Interculturalism as a paradigm for thinking about diversity'. Intercultural Education, 17 (5), 475-83.

Alexander, R.J. (2008) Towards Dialogic Teaching: Rethinking classroom talk. 4th ed. Thirsk: Dialogos.

Aronowitz, S. and Giroux, H.A. (2003) Postmodern Education: Politics, culture, and social criticism. Minneapolis: University of Minnesota Press.

Bakhtin, M.M. (1986) Speech Genres and Other Late Essays. Ed. Holquist, M. and Emerson, C. Trans. McGee, V.W. Austin: University of Texas Press.

Biesta, G. (2014) 'Pragmatising the curriculum: Bringing knowledge back into the curriculum conversation, but via pragmatism'. Curriculum Journal, 25 (1), $29-49$.

Buber, M. (1958) I and Thou. Trans. Smith, R.G. 2nd ed. Edinburgh: T. and T. Clark.

Council of Europe (2008) White Paper on Intercultural Dialogue: "Living together as equals in dignity". Strasbourg: Council of Europe. Online. https://tinyurl.com/yxs2tqaq (accessed 7 August 2019).

DIALLS (Dlalogue and Argumentation for Cultural Literacy Learning in Schools) (2018) Cultural Analysis Framework. Online. https://tinyurl.com/y6fdwmq7 (accessed 7 August 2019).

Edwards, A.T. (1984) 'Cultural literacy: What are our goals?'. The English Journal, 73 (4), 71-2.

Freire, P. (2000) Pedagogy of the Oppressed. Trans. Ramos, M.B. New York: Continuum.

Freire, P. and Macedo, D. (1987) Literacy: Reading the word and the world. London: Routledge and Kegan Paul.

Giroux, H.A. (1992) Border Crossings: Cultural workers and the politics of education. New York: Routledge.

Graff, H.J. (1989) 'Critical literacy versus cultural literacy: Reading signs of the times?'. Interchange, 20 (1), 46-52.

Hendley, B. (1989) 'Hirsch and Dewey on democracy and education'. Interchange, 20 (1), 53-60.

Hirsch, E.D. (1980) 'Culture and literacy'. Journal of Basic Writing, 3 (1), $27-47$.

Hirsch, E.D. (1988) Cultural Literacy: What every American needs to know. New York: Vintage Books.

Kaufer, D.S. (1989) 'Cultural literacy: A critique of Hirsch and an alternative theory'. ADE Bulletin, 94, 23-8.

Lähdesmäki, T. (2012) 'Rhetoric of unity and cultural diversity in the making of European cultural identity'. International Journal of Cultural Policy, 18 (1), 59-75.

Lambert, D. (2011) 'Reviewing the case for geography, and the "knowledge turn" in the English national curriculum'. Curriculum Journal, 22 (2), 243-64.

Löfgren, O. (1989) 'The nationalization of culture'. Ethnologia Europaea, 19 (1), 5-24.

Malkki, L. (1992) 'National geographic: The rooting of peoples and the territorialization of national identity among scholars and refugees'. Cultural Anthropology, 7 (1), $24-44$.

Malkki, L.H. (1995) 'Refugees and exile: From "refugee studies" to the national order of things'. Annual Review of Anthropology, 24, 495-523.

McLaren, P. (1998) Life in Schools: An introduction to critical pedagogy in the foundations of education. 3rd ed. New York: Longman.

New London Group (1996) 'A pedagogy of multiliteracies: Designing social futures'. Harvard Educational Review, 66 (1), 60-92.

Otten, M. (2003) 'Intercultural learning and diversity in higher education'. Journal of Studies in International Education, 7 (1), 12-26.

Portera, A. (2008) 'Intercultural education in Europe: Epistemological and semantic aspects'. Intercultural Education, 19 (6), 481-91. 
Riecken, T.J. and Court, D. (1992) 'Extending cultural literacy'. Journal of Educational Thought, $26(2), 152-63$.

Scott, D. (2014) 'Knowledge and the curriculum'. Curriculum Journal, 25 (1), 14-28.

Street, B.V. (1984) Literacy in Theory and Practice. Cambridge: Cambridge University Press.

Street, B. (2003) 'What's "new" in New Literacy Studies? Critical approaches to literacy in theory and practice'. Current Issues in Comparative Education, 5 (2), 77-91.

Swift, D. (2017) 'The challenges of developing disciplinary knowledge and making links across the disciplines in early years and primary humanities'. Education 3-13, 45 (3), 365-74.

UNESCO (United Nations Educational, Scientific and Cultural Organization) (1996) 'Learning: The treasure within: Report to UNESCO of the International Commission on Education for the Twenty-First Century'. Online. https://tinyurl.com/oqlzaw3 (accessed 7 August 2019).

Vertovec, S. (2007) 'Super-diversity and its implications'. Ethnic and Racial Studies, 30 (6), 1024-54.

Wegerif, R. (2007) Dialogic Education and Technology: Expanding the space of learning. New York: Springer.

Wegerif, R. (2010) 'Dialogue and teaching thinking with technology: Opening, expanding and deepening the "inter-face"'. In Littleton, K. and Howe, C. (eds) Educational Dialogues: Understanding and promoting productive interaction. London: Routledge, 304-22.

Wegerif, R. (2011) 'Towards a dialogic theory of how children learn to think'. Thinking Skills and Creativity, 6 (3), 179-90.

Wegerif, R. (2016) 'Dialogue with a tree?'. Online. www.rupertwegerif.name/blog/dialogue-with-a-tree (accessed 7 January 2019).

Wegerif, R. (2018) 'Dialogue and equality'. Online. www.rupertwegerif.name/blog/dialogue-and-equality (accessed 7 January 2019).

Wegerif, R. and Major, L. (2019) 'Buber, educational technology, and the expansion of dialogic space'. Al and Society, 34 (1), 109-19.

Wiesand, A., Heiskanen, I., Mitchell, R., Cliché, D., Fisher, M. and Marsio, L. (2008) Sharing Diversity: National approaches to intercultural dialogue in Europe: Study for the European Commission. Bonn: European Institute for Comparative Cultural Research.

Woodhouse, H.R. (1989) 'Critical reflections on Hirsch and cultural literacy'. Interchange, 20 (3), 80-9.

Young, M. (2009) 'What are schools for?'. In Daniels, H., Lauder, H. and Porter, J. (eds) Knowledge, Values and Educational Policy: A critical perspective. London: Routledge, 10-18.

Young, M., Lambert, D., Roberts, C. and Roberts, M. (2014) Knowledge and the Future School: Curriculum and social justice. London: Bloomsbury Academic. 